\title{
EMBRYO MORTALITY IN THE HEAT STRESSED EWE
}

\author{
II. APPLICATION OF HOT-ROOM RESULTS TO \\ FIELD GONDITIONS
}

\author{
C. J. THWAITES* \\ John Hammond Climate Laboratory, Department of Livestock Husbandry, \\ University of New England, Armidale, New South Wales, Australia
}

(Received 30th May 1968)

\begin{abstract}
Summary. Continuous hot-room exposure during the first 15 days of pregnancy raised the rectal temperatures and respiratory rates of mature Merino ewes to about 104 to $105^{\circ} \mathrm{F}$ and 170 respirations/min respectively and led to the death of $83 \%$ of embryos.

Similar ewes subjected to a diurnally variable heat stress, which raised their rectal temperatures and respiratory rates to about 104 to $105^{\circ} \mathrm{F}$ and 220 respirations/min during an 8-hr 'day' and allowed them to fall to about $102^{\circ} \mathrm{F}$ and 140 respirations/min respectively during a subsequent 16-hr 'night', experienced an embryo mortality rate of only $35 \%$.

Control ewes, housed similarly, but at natural temperatures 33 to $65^{\circ} \mathrm{F}$ ), had rectal temperatures and respiratory rates of about 101 to $102^{\circ} \mathrm{F}$ and 20 respirations/min, respectively, and suffered the loss of $19 \%$ of their ova.

The results illustrate the mitigating effects of a daily period of respite from high temperatures and indicate that this, rather than differences in acclimatization to heat and lack of radiant heating in the hot-room, is the major factor to be considered when comparing the effects on embryo mortality of heat stress in the field with those of periods of continuous heat stress in the hot-room.
\end{abstract}

\section{INTRODUCTION}

Numerous hot-room studies (Dutt, Ellington \& Carlton, 1959; Alliston \& Ulberg, 1961; Dutt, 1963; Smith, Bell \& De Chaneet, 1966; Thwaites, 1967a; and others) have demonstrated that ewes subjected to continuous heat stress during early pregnancy may suffer high embryo mortality rates. However, similarly raised embryo mortality rates are generally not encountered in comparable ewes under hot conditions in the field (Shelton, 1964; Smith, 1964; Smith et al., 1966). The hot-room and field observations referred to differ in three major respects: the time of year at which the observations were made, the degree of acclimatization to heat experienced by the ewes before conception, and the nature and extent of the heat stress experienced by the ewes. It

* Present address: Department of Agriculture, The University, Reading, England. 
seems likely that differences in embryo mortality rate between ewes under the two sets of conditions are related to one or more of these factors.

In an attempt, presumably, to maximize the fertility and fecundity of a limited number of experimental ewes, the hot-room studies cited have been conducted during the peak of the annual oestrous season, the autumn and early winter months. On the other hand, the field observations have of necessity been confined to the hottest period of the year, the summer. There is no reason to suspect, however, that this seasonal difference would have influenced the rate of embryo mortality experienced by the different ewes other than through seasonal differences in acclimatization to heat.

In each of the hot-room studies cited, the experimental ewes were relatively unadapted to high temperatures. It seems reasonable to suppose that adaptation to heat, as would occur in ewes under field conditions in summer, would mitigate the embryocidal effects of high ambient temperature. Smith et al. (1966) have suggested this as a possible reason for the discrepancy between results in the hot-room and in the field, and for the failure of high temperature to raise the embryo mortality rate significantly in the experiment of Ryle (1961) in which an attempt was made to acclimatize the experimental ewes to high temperatures.

The heat stress used in each of the hot-room experiments under discussion differed in both nature and extent from that which occurs in the field. Smith et al. (1966) exposed ewes to high temperature for 7 days, and pointed out that such a protracted period of heat stress was unlikely to occur under natural conditions, at least in Australia. The other hot-room studies reported have been of even longer duration. Unfortunately, critical data on the effect of duration of heat stress on embryo mortality in the ewe are not yet available. However, the work of Dutt (1963) reveals that ovine embryos are most susceptible to maternal heat stress during the first few days after fertilization, while unpublished work of the present author has shown that the reproductive performance of Dorset Horn $\times$ Merino ewes is unaffected by a 24-hr period of severe heat stress imposed immediately after fertilization.

Solar radiation and diurnal variation are two important components of heat stress in the field. In the hot-room experiments in question, the atmospheric conditions were maintained constant throughout a $24-\mathrm{hr}$ period. The absence of solar radiation from the above hot-room studies is not a major obstacle in the interpretation of the results obtained if it is assumed that radiant heat has no specific effect on embryo mortality but exerts its influence through changes in body temperature. However, while this assumption is supported by the limited amount of available evidence, it must be remembered that hot/wet and hot/dry climates give rise to different respiratory rate/body temperature relationships (Klemm, 1962; Thwaites, 1967b). In the absence of knowledge of the mechanism of heat-induced embryo mortality in the ewe (Thwaites, 1968c), it is not possible to assess the precise importance of such differences as far as embryo mortality is concerned, although it seems unlikely that they could have more than a marginal effect.

Finally, there is the difference between the natural heat stress of diurnal variation and the continuous heat stress imposed on ewes in the various hot- 
room experiments. A regular period of respite from high temperature is known to lessen the adverse effects of high temperature on feed intake and foetal body size (Alexander \& Williams, 1966), wool growth (Thwaites, 1968b) and spermatogenesis (Oloufa, Bogart \& McKenzie, 1949). The experiments described were thus undertaken to examine the possibility that the presence of relatively cool nights between successive hot days could be a major factor in the absence of high embryo mortality rates in ewes mated under hot conditions in the field.

\section{MATERIALS AND METHODS}

As only one hot-room was available, it was not possible to compare the effects of continuous and diurnally variable heat stresses concurrently. Two separate experiments were therefore conducted, in which similar ewes were used and in which the interval between experiments was reduced to the practical minimum.

\section{Animals}

Seventy-two Merino ewes, aged 5 to 6 years, were placed in yards with raddled vasectomized rams on 1st May 1967. The ewes ranged in weight from 31.0 to $42.0 \mathrm{~kg}$ (mean $=35.1 \mathrm{~kg}$ ) and were subsequently maintained at this weight on a ration of equal parts lucerne chaff and concentrates which was fed communally at 17.30 hours daily.

\section{Oestrus synchronization, fertile mating and allocation to groups}

To facilitate subsequent procedures, oestrus was synchronized in the ewes of both experiments. Synchronization was achieved by a series of eight intramuscular injections of $20 \mathrm{mg}$ progesterone in $2 \mathrm{ml}$ peanut oil administered between 09.00 and 10.00 hours every second day. Checks for ewes in oestrus during and after progesterone treatment were made daily at 08.30 and 17.30 hours.

In order to avoid any adverse effects which exogenous progesterone may have had on fertility, fertile mating was delayed until the second oestrus after progesterone treatment. At 07.00 hours on Day 15 of the oestrous cycle after initial synchronization, the ewes were placed indoors in well-lit and ventilated rooms with vasectomized rams raddled with a fresh colour. From this time until the end of mating, checks for oestrus were made at 07.00 and 19.00 hours daily. At each check, ewes in oestrus were mated to fertile rams; two rams at the first check and a different ram at each subsequent check at which the ewes remained in oestrus.

In each experiment, the required number of ewes was allocated to groups at the first check at which they would no longer stand for the ram. Surplus ewes were discarded. Ewes within groups were considered as replicates and the ewes for each replicate were randomly assigned to groups.

\section{Determination of ovulation and embryo mortality rates}

All ewes were killed on Day 15 . The ovaries and uteri were recovered, placed in warm saline, and taken to the laboratory and examined within $15 \mathrm{~min}$ of death. The number of corpora lutea (GL) and their location were recorded and 
the ovaries were trimmed and weighed. The CL were removed from the ovaries (blunt dissection), weighed, halved, measured and placed in fixative. The uteri were then examined for the presence of embryos or embryonic remains by opening the entire length of both horns by means of a tearing procedure as sharp cutting instruments were found to damage the fragile, 15-day, embryonic membranes. Recovered embryos were photographed and examined under a dissecting microscope. The criteria used for the classification of embryos were length and size of membranes and degree of differentiation of the embryo. No heartbeat or membrane vasculature is normally visible on Day 15.

\section{Indices of heat stress}

As a measure of the stress imposed on the ewes by the different hot-room conditions, rectal temperatures (clinical thermometer inserted $10 \mathrm{~cm}$ for $1 \mathrm{~min}$ ) and respiration rates (sum of two $\frac{1}{2}$-min flank movement counts) were recorded at the times indicated below.

\section{Experiment 1}

Ewes for this experiment were shorn and received their first oestrus-synchronizing progesterone injection on 1st May 1967. Fertile mating took place between 3rd and 7th June, and the ewes were killed between 19th and 23rd June 1967. Twenty-four ewes were available for use in the experiment, and these were divided into three groups of eight: one control and two hot-room groups. Control ewes were maintained indoors under natural temperature conditions (minimum temperature $=46^{\circ} \mathrm{F}$, maximum temperature $=63^{\circ} \mathrm{F}$ ) while the hot-room groups were exposed to a diurnally variable heat stress which was designed to reproduce the diurnal rectal temperature/respiratory rate patterns encountered under hot conditions in the field. To this end, each 24-hr cycle in the hot-room was divided into an 8-hr 'day' and a 16-hr 'night'. At 09.00 hours daily, the hot-room controls were set at $106.0^{\circ} \mathrm{F}$ and $40 \%$ relative humidity and at 17.00 hours daily, these settings were reduced to $95^{\circ} \mathrm{F}$ and $30 \%$ relative humidity. The hot-room's automatic controls were such that temperature and relative humidity fluctuated over a range of $3.3^{\circ} \mathrm{F}$ and $4 \%$, respectively, with a cycle length of $15 \mathrm{~min}$.

The rectal temperatures and respiratory rates of all ewes were recorded at 09.00 and 17.00 hours on Days 1, 7 and 14. One of the hot-room groups received no additional treatment while the other received progesterone therapy as part of another study (Thwaites, 1968c).

\section{Experiment 2}

The ewes for this experiment received their first oestrus-synchronizing progesterone injection on 9th June 1967. Fertile mating took place between 13th and 16th July and the ewes were killed between 29th July and 1st August 1967. Thirty-two ewes were available for the experiment, in which a $2 \times 2 \times 2$ factorial design was adopted in order to investigate the influences of fleece length and progesterone therapy (Thwaites, 1968c) on embryo mortality under control and hot-room conditions.

Control ewes were maintained under prevailing indoor temperature condi- 
tions (minimum temperature $33^{\circ} \mathrm{F}$, maximum temperature $65^{\circ} \mathrm{F}$ ) while the hot-room groups were exposed continuously for 14 days to mean hot-room conditions of $96.5 \% \mathrm{~F}$ and $63 \%$ relative humidity. The rectal temperatures and respiratory rates of all ewes were recorded at 14.00 hours on the day of oestrus and on Days 1, 7 and 14 of hot-room exposure.

Within the control and hot-room groups, 'shorn' and 'unshorn' sub-groups were formed from ewes having fleece lengths of 0.5 and $5 \mathrm{~cm}$ respectively. Half of each fleece length sub-group received daily intramuscular injections of $15 \mathrm{mg}$ progesterone in $1 \mathrm{ml}$ peanut oil from Day 1 to Day 15; the other half received injections of the vehicle only.

\section{RESULTS}

Synchronization of oestrus

In Expts. 1 and 2,91.4\% and 86.1\% of ewes were in oestrus within the period from 3 to 6 days after the final oestrus-synchronizing progesterone injection. Corresponding figures for ewes in oestrus at the second cycle were 97.1 and $94 \cdot 4 \%$ respectively.

\section{Rectal temperature and respiratory rate}

Experiment 1. Rectal temperatures in the control ewes did not vary significantly between days during the course of the experiment, but they were higher at 17.00 hours than at 09.00 hours $\left(102.0 \pm 0.1\right.$ versus $\left.101 \cdot 1 \pm 0.2^{\circ} \mathrm{F} ; P<0.001\right)$. The respiratory rate of these ewes averaged $19 \cdot 0 \pm 1 \cdot 2$ respirations/min and did not vary significantly with either time of day or day of experiment.

TABLE 1

RECTAL TEMPERATURES AND RESPIRATION RATES OF CONTROL AND HOT-ROOM EWES IN EXPERIMENT 1

\begin{tabular}{|c|c|c|c|c|}
\hline Time & Group & Day 1 & Day 7 & Day 14 \\
\hline \multirow[t]{2}{*}{$\begin{array}{l}09.00 \\
\text { hours }\end{array}$} & Control & $\begin{array}{c}101.5 \pm 0.3 * \\
16.5 \pm 0.3 \dagger\end{array}$ & $\begin{array}{r}101.2 \pm 0.3 \\
15.6 \pm 1.2\end{array}$ & $\begin{array}{r}100 \cdot 7 \pm 0 \cdot 3 \\
24 \cdot 0 \pm 6 \cdot 4\end{array}$ \\
\hline & Hot-room & $\begin{array}{l}102 \cdot 4 \pm 0 \cdot 2 \\
142 \cdot 8 \pm 5 \cdot 4\end{array}$ & $\begin{array}{ll}102 \cdot 3 \pm & 0 \cdot 2 \\
163 \cdot 4 \pm & 8 \cdot 2\end{array}$ & $\begin{array}{l}102 \cdot 0 \pm 0 \cdot 3 \\
138 \cdot 1 \pm 11 \cdot 8\end{array}$ \\
\hline \multirow[t]{2}{*}{$\begin{array}{l}17 \cdot 00 \\
\text { hours }\end{array}$} & Control & $\begin{array}{r}102 \cdot 4 \pm 0 \cdot 2 \\
20 \cdot 5 \pm 1 \cdot 1\end{array}$ & $\begin{aligned} 102.2 \pm & 0.2 \\
18.2 \pm & 1.1\end{aligned}$ & $\begin{array}{r}102 \cdot 0 \pm 0 \cdot 2 \\
18 \cdot 9 \pm 2 \cdot 4\end{array}$ \\
\hline & Hot-room & $\begin{array}{l}105 \cdot 4 \pm 0 \cdot 3 \\
222 \cdot 0 \pm 9 \cdot 2\end{array}$ & $\begin{array}{l}104 \cdot 0 \pm 0 \cdot 2 \\
219 \cdot 4 \pm 11 \cdot 1\end{array}$ & $\begin{array}{l}104 \cdot 0 \pm 0.2 \\
231 \cdot 0 \pm 9 \cdot 7\end{array}$ \\
\hline
\end{tabular}

As can be seen from Table 1, both parameters in the hot-room were substantially increased at the end of the 8-hr hot-room day $(P<0 \cdot 001)$. The rectal temperatures recorded at this time were less on Days 7 and 14 than they were on Day $1(P<0.01)$, although no such effect was apparent in the respiratory rate data. Both rectal temperatures and respiratory rates declined $(P<0.001)$ during the hot-room night. At 09.00 hours the rectal temperatures of ewes in 
the hot-room approached those of controls but their respiratory rates remained higher.

Experiment 2. The rectal temperatures of control ewes were not significantly affected by either fleece length, progesterone therapy or day of experiment (Table 2) and averaged $101 \cdot 8 \pm 0 \cdot 1^{\circ} \mathrm{F}$. As might be expected (e.g. Klemm, 1962), the respiratory rates of the control shorn sub-group were lower than those in the unshorn sub-group $(14 \cdot 2 \pm 0 \cdot 3$ versus $28 \cdot 0 \pm 2 \cdot 8 ; P<0 \cdot 01)$.

\section{TABLE 2}

REGTAL TEMPERATURES AND RESPIRATION RATES OF GONTROL AND HOT-ROOM EWES IN EXPERIMENT 2

\begin{tabular}{|c|c|c|c|c|c|}
\hline Group & Sub-group & Day 0 & Day 1 & Day 7 & Day 14 \\
\hline \multirow[t]{2}{*}{ Control } & Shorn & $\begin{array}{r}102 \cdot 1 \pm 0 \cdot 4^{*} \\
14 \cdot 8 \pm 1 \cdot 0 \dagger\end{array}$ & $\begin{array}{r}101 \cdot 8 \pm 0.4 \\
14 \cdot 1 \pm 0.8\end{array}$ & $\begin{aligned} 101.8 \pm & 0.4 \\
13.5 \pm & 1.4\end{aligned}$ & $\begin{array}{r}101 \cdot 1 \pm 0.4 \\
14 \cdot 1 \pm 0.9\end{array}$ \\
\hline & Unshorn & $\begin{array}{r}102 \cdot 4 \pm 0 \cdot 5 \\
26 \cdot 9 \pm 2 \cdot 2\end{array}$ & $\begin{array}{r}101 \cdot 8 \pm 0 \cdot 5 \\
22 \cdot 1 \pm 2 \cdot 1\end{array}$ & $\begin{array}{r}101 \cdot 8 \pm 0 \cdot 3 \\
29 \cdot 8 \pm 10 \cdot 3\end{array}$ & $\begin{array}{r}101 \cdot 2 \pm 0 \cdot 5 \\
32 \cdot 7 \pm 18 \cdot 1\end{array}$ \\
\hline \multirow[t]{2}{*}{ Hot-room } & Shorn & $\begin{array}{r}102.2 \pm 0.3 \\
13.9 \pm 0.7\end{array}$ & $\begin{array}{l}103 \cdot 0 \pm 0 \cdot 6 \\
175 \cdot 3 \pm 20 \cdot 4\end{array}$ & $\begin{array}{l}103 \cdot 6 \pm 0 \cdot 3 \\
177 \cdot 3 \pm 9 \cdot 4\end{array}$ & $\begin{array}{l}103 \cdot 6 \pm 0 \cdot 2 \\
169 \cdot 7 \pm 9 \cdot 3\end{array}$ \\
\hline & Unshorn & $\begin{array}{r}102 \cdot 2 \pm 0 \cdot 2 \\
25 \cdot 7 \pm 2 \cdot 5\end{array}$ & $\begin{array}{l}103 \cdot 5 \pm 0.5 \\
181 \cdot 5 \pm 7.5\end{array}$ & $\begin{array}{l}104 \cdot 9 \pm 0.4 \\
161.7 \pm 12 \cdot 9\end{array}$ & $\begin{array}{ll}104 \cdot 8 \pm 0 \cdot 2 \\
152 \cdot 3 \pm & 0 \cdot 2\end{array}$ \\
\hline
\end{tabular}

* Rectal temperature $\left({ }^{\circ} \mathbf{F}\right)$.

† Respirations/min.

TABLE 3

CORPORA LUTEA AND 15-DAY EMBRYOS AND EMBRYONIC REMAINS

\begin{tabular}{|c|c|c|c|c|}
\hline & \multicolumn{2}{|c|}{ Control } & \multicolumn{2}{|c|}{ Hot-room } \\
\hline $\begin{array}{l}\text { EXPERIMENT } 1 \\
\text { No. of ewes } \\
\text { No. of CL } \\
\text { No. of viable 15-day embryos } \\
\text { No. of degenerate } 15 \text {-day embryos } \\
\% \text { CL not represented by viable } 15 \text {-day embryos }\end{array}$ & \multicolumn{2}{|c|}{$\begin{array}{c}8 \\
9 \\
7 \\
0 \\
22 \cdot 2\end{array}$} & \multicolumn{2}{|c|}{$\begin{array}{c}16 \\
17 \\
11 \\
3 \\
35 \cdot 3\end{array}$} \\
\hline $\begin{array}{l}\text { EXPERLMENT } 2 \\
\text { No. of ewes } \\
\text { No. of cL } \\
\text { No. of viable } 15 \text {-day embryos } \\
\text { No. of degenerate } 15 \text {-day embryos } \\
\% \text { cL not represented by viable } 15 \text {-day embryos }\end{array}$ & $\begin{array}{c}\text { Shorn } \\
8 \\
8 \\
8 \\
0 \\
0\end{array}$ & $\begin{array}{l}\text { Unshorn } \\
8 \\
9 \\
6 \\
2 \\
33 \cdot 3\end{array}$ & $\begin{array}{c}\text { Shorn } \\
8 \\
9 \\
3 \\
4 \\
66 \cdot 6\end{array}$ & $\begin{array}{l}\text { Unshorn } \\
8 \\
9 \\
0 \\
2 \\
100 \cdot 0\end{array}$ \\
\hline
\end{tabular}

The rectal temperatures and respiratory rates of ewes in the hot-room averaged $103.9 \pm 0.2^{\circ} \mathrm{F}$ and $168 \cdot 6 \pm 4.7$ respirations $/ \mathrm{min}$, respectively and were higher $\langle P<0.01$ and $P<0.001$, respectively) than corresponding values in controls. There were no significant day of experiment, fleece length or progesterone effects on these parameters in the hot-room.

\section{Reproductive performance}

Progesterone therapy did not significantly influence the reproductive performance of ewes in either experiment and the results presented in Table 3 have 
therefore been pooled with respect to this parameter. In Expt. 1, exposure to diurnally variable heat stress for 14 days did not significantly depress the reproductive performance of heated ewes and the rate of ovum loss of all ewes, $30.8 \%$, was comparable to that reported for control groups of similar ewes in previous years (Thwaites, 1967a, 1968a). In contrast to this, continuous hotroom exposure in Expt. 2 gave rise to a substantial increase in the proportion of ova not represented by viable 15 -day embryos $(P<0 \cdot 001)$, even though the rectal temperatures and respiratory rates of hot-room ewes did not reach the levels experienced by their counterparts in Expt. 1 at the end of each hot-room day.

It will be seen from Table 3 that, in Expt. 2, unshorn ewes had fewer viable 15-day embryos than shorn ewes under both control and hot-room conditions. These differences just failed to reach significance $\left(\chi^{2}=3.24\right.$ and $3 \cdot 60$, respectively, $0.05<P<0 \cdot 10)$. However, with respect to the total number of embryos (viable and non-viable) present on Day 15, the performance of shorn ewes was significantly better than that of unshorn ewes under hot-room conditions $\left(\chi^{2}=5.56,0.01<P<0.02\right)$.

\section{DISCUSSION}

The difference between the results from these two experiments, which were conducted under similar conditions during the same season of the year and on ewes of similar genetic constitution and thermal history, highlights the effectiveness of a relatively cool night in ameliorating the adverse effects of high daytime temperatures. The magnitude of this difference suggests that the diurnally variable component of natural heat stress is a major factor to be considered when comparing embryo mortality rates in ewes exposed to continuous heat stress in the hot-room and to natural heat stress in the field. The results also offer an explanation for the failure of heat stress to raise embryo mortality rates significantly in Merino ewes in the experiments of Yeates (1956) and Ryle (1961). In both these experiments, a diurnally variable heat stress was imposed on experimental hot-room ewes.

As marked diurnal variations in both ambient temperature and radiant heat occur under natural conditions, the present results indicate that, in the field, heat-induced embryo mortality might occur in appreciable numbers of Merino ewes only under severe heatwave conditions. This indication is supported by the fact that any ameliorating influence of acclimatization to heat would still further reduce the occurrence of embryo mortality.

The observation that a greater proportion of the shorn than of the unshorn ewes in the hot-room was able to sustain embryo development to a stage which ensured that embryonic remains were present on Day 15 was in agreement with that of Dutt et al. (1959), who reported a similar, though non-significant tendency for shorn ewes to have higher fertilization rates, lower numbers of abnormal ova and a larger lamb crop than unshorn ewes when they were heated for various intervals before and after mating. This difference was attributed to the fact that shorn ewes had lower rectal temperatures than unshorn ewes under hot-room conditions (difference about $0.8^{\circ} \mathrm{F}$, non-significant). A similar 
situation applied amongst hot-room ewes in Expt. 2 of this study (Table 2), and this is the only apparent explanation for their superior reproductive performance. Under field conditions, however, it might be anticipated that unshorn ewes would be at an advantage because of the protection afforded them against radiant heat by the presence of the fleece (Macfarlane, Morris \& Howard, 1958; Parer, 1963; Thwaites, 1967b).

\section{ACKNOWLEDGMENTS}

The project was supported by grants from the Australian Wool Research Trust Fund and from the University of New England.

\section{REFERENCES}

Alexander, G. \& Williams, D. (1966) Heat stress and growth of the conceptus in sheep. Proc. Aust. Soc. Anim. Prod. 6, 102.

Alliston, C. W. \& Ulberg, L. G. (1961) Early pregnancy loss in sheep at ambient temperatures of $70^{\circ}$ and $90^{\circ} \mathrm{F}$ as determined by embryo transfer. F. Anim. Sci. 20, 608 .

Dutr, R. H. (1963) Critical period for early embryo mortality in ewes exposed to high ambient temperature. 7. Anim. Sci. 22, 713.

Dutt, R. H., Ellington, E. F. \& Carlton, W. W. (1959) Fertilization rate and early embryo survival in sheared and unsheared ewes following exposure to elevated air temperature. F. Anim. Sci. 18, 1308.

KLEMM, G. H. (1962) The reactions of unshorn and shorn sheep to hot wet and hot dry atmospheres. Aust. J. agric. Res. 13, 472.

Macfarlane, W. V., Morris, R.J. H. \& Howard, B. (1958) Heat and water in tropical Merino sheep. Aust. F. agric. Res. 9, 217.

Oloura, M. M., Bogart, R. \& McKenzie, F. F. (1949) The effects of environmental temperature and the thyroid gland on fertility in male rabbits. $\mathcal{F}$. Anim. Sci. 8,644 .

Parer, J. T. (1963) Wool length and radiant heating effects in sheep. F. agric. Sci., Camb. 60, 141.

RYLE, M. (1961) Early reproductive failure of ewes in a hot environment. I. Ovulation rate and embryonic mortality. F. agric. Sci., Camb. 57, 1.

Shelton, M. (1964) Relation of environmental temperature during gestation to birth weight and mortality of lambs. F. Anim. Sci. 23, 360.

Smith, I. D. (1964) Reproduction in Merino sheep in tropical Australia. Aust. vet. F. 40, 156.

Smith, I. D., Bell, G. H. \& De Chaneet, G. (1966) Embryonic mortality in Merino ewes exposed to high ambient temperatures. Aust. vet. F. 42, 468.

Thwartes, C. J. (1967a) Embryo mortality in the heat stressed ewe. I. The influence of breed. $\mathcal{F}$. Reprod. Fert. 14, 5.

Thwartes, C. J. (1967b) Fleece length and the reactions of sheep to elevated humidity and radiant heating at high ambient temperatures. Res. vet. Sci. 8, 463.

THwartes, C.J. (1968a) The influence of age of ewe on embryo mortality under heat stress conditions. Int. F. Biomet. 12, 29.

Thwaites, C. J. (1968b) Heat stress and wool growth in sheep. Proc. Aust. Soc. Anim. Prod. 7, 259.

Thwartes, C. J. (1968c) Luteal regression and embryo mortality in the heat-stressed Merino ewe. Proc. 2nd World Conf. Anim. Prod. (in press).

Yeates, N. T. M. (1956) The effect of high air temperature on pregnancy and birth weight in Merino sheep. Aust. 7. agric. Res. 7, 435. 